\title{
Õpetajate koostöise õpikultuuri kogemused Eesti üldhariduskoolide näitel
}

\author{
Pille Slabina $^{\mathrm{a}}$, Katrin Aava ${ }^{\mathrm{b}}$ \\ ${ }^{a}$ Tallinna Ülikooli haridusteaduste instituut \\ ${ }^{b}$ Tallinna Ülikooli Balti filmi, meedia, kunstide ja kommunikatsiooni instituut
}

\begin{abstract}
Annotatsioon
Koostöine õpikultuur võimestab õpetajaid, suurendab eneseusaldust, annab julgust situatsioone juhtida ja suurendab agentsust. Uurimuse eesmärk on välja selgitada õpetajate koostöökultuuri kogemused. Kriitilist diskursuseanalüüsi kasutades kirjeldame, kuidas 15 üldhariduskooli 45 õpetajat konstrueerivad koostöise õpikultuuri kogemust individuaalsel, suhtlus- ja sotsiaalsel tasandil ning väljendavad enda agentsust. Uuringus eendus agentsete õpetajate koostöise õpikultuuri diskursus, mille aluseks on üksteiselt õppimine, mittevõistlev keskkond, usalduslikud suhted ja tunnustamine. Konkurentsidiskursusele on omane piiratud koostöö, kuna kolleegides või juhtides nähakse takistusi. Võimestamata õpetaja diskursust iseloomustavad ei-sõnumid ja agentsuse puudumine: sellised õpetajad ei usu koostöösse, neil puuduvad head koostöökogemused, nad ei koge kolleegide ega juhtkonna toetust-tunnustust.
\end{abstract}

Võtmesõnad: koostöine õpikultuur, agentsus, õpetajad, kriitiline diskursuseanalüüs

\section{Sissejuhatus}

„Eesti elukestva õppe strateegia 2020“ (2014) kohaselt asendub kooli traditsiooniline õppevorm senisest rohkem meeskonnatööga. Strateegiadokumentides olulised teadmusühiskonna ja õppiva organisatsiooni ideed on ühiskonna arengu seisukohalt võtmetähtsusega, eeldades jagatud arusaamu, mõtte-, suhtlus- ja tegutsemisviiside muutust, eelkõige võimekust teha praktikas koostööd (Collinson \& Fedoruk Cook, 2007; Fullan, 2009; Lepik, Loogma, \& Talts, 2013). Samas on 1990ndatel uusliberaalsete põhimõtete mõjul eelkõige konkurents,

Haridusteaduste instituut, Tallinna Ülikool, Narva mnt 25, 10120 Tallinn;

pille.slabina@tlu.ee 
mitte koostöö kujunenud hariduselus peamiseks igapäevaelu praktikaks (Fejes, 2008; Loogma, Tafel-Viia, \& Ümarik, 2012; Põlda \& Aava, 2016; Spring, 2004). Ka Eesti õpetajad seisavad silmitsi vastuoluliste ülesannetega: ühelt poolt tuleb õppijatele läheneda individuaalselt, aga teisalt konkureerida õpitulemuste põhjal teistega (Timoštšuk, Ugaste, \& Mets-Alunurm, 2018). Sellises olukorras toimetulekuks saab õpetaja tuge lähematelt kolleegidelt, aga ta vajaks senisest enam tunnustamist ühiskonnas (ibid.). Samuti näitavad uuringud, et osa Eesti õpetajatest võtab muutused entusiastlikult omaks, teised kohanduvad või ignoreerivad neid (Lepik et al., 2013).

Rahvusvahelise õpetamise ja õppimise uuringu TALIS $(2008,2013)$ kohaselt ei tee Eesti õpetajad piisavalt professionaalset koostööd, näiteks kolmandik õpetajatest pole kunagi külastanud kolleegide tunde, andnud neile tagasisidet ega õpetanud ühtse meeskonnana samas klassis. Samas on just õpetajate koostöine õppimine, peamiselt professionaalsed koostöövõrgustikud, oluline tugi haridusmuutustega kohanemisel ning nende mõtestamisel ja omaksvõtmisel (Brouwer, Brekelmans, Nieuwenhuis, \& Simons, 2012; Daly, Moolenaar, Bolivar, \& Burke, 2010; Hargreaves, 2006). Koostöövõrgustikes tegutsemine annab õpetajale suurema vastutuse nii organisatsioonis kui ka ühiskonnas laiemalt toimuvate muutuste eest, kujundades seeläbi ka usalduslikumaid ja toetavamaid suhteid õpetajate endi vahel (Forte \& Flores, 2014; Johns-Shepherd \& Gowing, 2007). Seda kinnitab ka Eestis tehtud kutseõpetajate koostöö uuring, mille põhjal eristusid omaette hoidvad, koolikesksed ja koostöövõrgustikes tegutsevad õpetajad, kusjuures viimased on enam rahul töö ja valitud ametiga (Sirk, Ümarik, Loogma, \& Niglas, 2017). Oluliseks peetakse kolleegide toetust: mida suurem see on, seda paremini õpetajad oma professionaalsust enda hinnangul edendavad (ibid.).

Õpetajatele on tähtis kolleegide ja ka juhtkonna tunnustus ning töö ühiste eesmärkide nimel (Timoštšuk et al., 2018). Kuigi enda tegevusele sisulise tagasiside saamine motiveerib õpetajaid enim, väitis 2008. aastal $28 \%$, aga 2013. aastal juba $43 \%$ õpetajatest, et nende tegevust tagasisidestatakse peamiselt administratiivsete formaalsuste täitmiseks (TALIS, 2008). Õpetajad tajuvad kaasatust kooli arendamisse juhtkonnast erinevalt: uuringu kohaselt nõustub $80 \%$ õpetajatest, et kool pakub õpetajatele võimalust aktiivselt osaleda kooli puudutavates otsustes, samas kui koolijuhtidest nõustub selle väitega 100\% (TALIS, 2013). Eesti õpetajate vähene enesetõhusus ja koostöö, austuse ning tunnustuse puudus on tihedalt seotud õpetajakutse staatusega ühiskonnas ning inimestevaheliste suhete vähese tähtsustamisega (TALIS, 2008). Seega saab varasemate uuringute põhjal osutada olulisele arenguülesandele, mis on seotud laiemalt hariduspoliitikaga ja kitsamalt koolis koostöise õpikultuuri kujundamisega. 


\section{Teoreetilised lähtekohad}

\section{Koostöine õpikultuur õppiva organisatsiooni kontekstis}

Koostöist õpikultuuri defineeritakse jagatud normide ja värrtuste, ühise õppeprotsessi kavandamise, reflekteeriva dialoogi, avalikustatud praktikate ja kogemuste jagamise kaudu (Hord, 1997). Koostöine õpikultuur hõlmab nii individuaalset, suhtlus- kui ka institutsionaalset tasandit (Euler, 2010; Feixas \& Zellweger, 2010). Individuaalsel tasandil kujundavad õpetajate hoiakud märgatavalt nende panust koostöötegevustesse (Vangrieken, Grosemans, Dochy, \& Kyndt, 2017). Ka suhtlustasandi eristamine on oluline, kuna organisatsioonis valitsev suhtlusstiil mõjutab õpetajate soovi võtta probleemide lahendajana vastutust (Scribner, Sawyer, Watson, \& Myers, 2007). Samuti mõjutab kooli juhtkond institutsionaalsel tasandil koostöö edukust märkimisväärselt (Forte \& Flores, 2014), võimaldades selleks ka toetavaid ressursse, nt aeg, koht (Vangrieken, Dochy, Raes, \& Kyndt, 2015).

Koostöine õpikultuur võimestab õpetajaid, suurendades nende eneseusaldust ja julgust situatsioone juhtida (Kohm \& Nance, 2009). Võimestamise kaudu suureneb õpetaja enesetõhusus, pühendumus, motivatsioon, mõjuvõim, ekspertsus (Cross, Davis, \& O’Neil, 2017, Luechauer \& Shulman, 1992) ja agentsus. Õpetaja agentsus sisaldab ajalist (professionaalne elulugu), kultuurilist (väärtused, uskumused, diskursus, keel), strukturaalset (suhted, roll, võim, usaldus) ja materiaalset dimensiooni (ressursid, keskkond) (Biesta, Priestley, \& Robinson, 2015). Seejuures on õpetaja agentsus, tegijapositsioon, enesetõhusus ja usk suutlikkusse saavutada eesmärke professionaalse identiteedi kujunemise seisukohast väga tähtsad ning seda mõjutavad oluliselt nii ühiskonnas kui ka töökeskkonnas valitsevad suhted (Ruus, 2010). Biesta jt (2015) rõhutavad ka ökoloogiliste tegurite tähtsust õpetaja agentsuse kujunemisel: nimelt on õpetaja mõjutatud keskkonnast ja organisatsioonis valitsevast õpikultuurist.

Õppiva organisatsiooni tunnuseid on kirjeldanud eri autorid (Collinson \& Fedoruk Cook, 2007; Kikoski \& Kikoski, 2004; Preskill \& Torres, 1999; Sarason, 1990; Senge, Cambron-McCabe, Lucas, Smith, \& Dutton, 2009; Senge, Kleiner, Roberts, Ross, \& Smith, 2014), kelle töödele toetudes on konkurentsipõhise ja óppiva organisatsiooni erinevused koondatud tabelitesse 1 ja 2 . Need erinevused avalduvad nii individuaalsel, suhtlus- kui ka institutsionaalsel tasandil. Individuaalsel tasandil esindavad õppivat organisatsiooni õpetaja hoiakud, mis toetavad meeskonnatööd, ning valmisolek võtta vastutus kooli arengu eest (tabel 1). Suhtlustasandil eristab õppivat organisatsiooni konkurentsipõhisest koostöö ja ideede jagamine, mis toetab muutustega kohanemist ja heade praktikate kiiret levikut. Õppivas organisatsioonis toimuvale koostööle on 
iseloomulik, et ohtlikest ja ebameeldivatest teemadest räägitakse tulemuslikult, dialoogi ja diskussiooni kaudu leitakse viisid ühiste eesmärkide saavutamiseks. Institutsionaalsel tasandil näevad õpetajad õppivas organisatsioonis ennast organisatsiooni eesmärkide teostajana, kuna protsesse käivitab õpetaja eneseteostus ja koostöine arendustegevus, koostöövõrgustikes tegutsemine (tabel 2).

Tabel 1. Koostöise õpikultuuri erinevused individuaalsel ja suhtlustasandil konkurentsipõhises ning õppivas organisatsioonis

\begin{tabular}{lll}
\hline \multicolumn{1}{c}{ Konkurentsipõhine organisatsioon } & Õppiv organisatsioon \\
\hline - Domineerib individuaalne pingutus & - Meeskonnatöö on väärtustatud \\
- Ideid jagatakse harva & - Ideede jagamine on üldlevinud \\
- Domineerib kogemuste ja lugude & - Dialoog võimaldab suurendada jagatud \\
jagamine & arusaama \\
- Jagamist kogetakse kui oma & Jagamist nähakse tavapärase osana \\
kompetentsuse äraandmist & professionaalses muutumises \\
- Uued ideed tekitavad kahtlusi & Uusi ideid testitakse kriitiliselt \\
- Jagamine toimub sõprade vahel & Ideed levivad eri viisidel, tasanditel \\
- Koostööd tehakse vähe & Koostöö on tihe, suurenenud \\
- Õpetajad näevad ennast vastutavana & Õpetajad näevad ennast vastutavana nii \\
klassiruumis toimuva eest & kooli kui ka enda professionaalse arengu \\
& eest \\
Õpetaja eelistab kindlustunnet ja on & Õpetaja on valmis muutusteks ja väldib \\
vastu muutustele & tööalast rutiini \\
\hline
\end{tabular}

Tabel 2. Koostöise õpikultuuri erinevused institutsionaalsel tasandil konkurentsipõhises ja õppivas organisatsioonis

\begin{tabular}{|c|c|}
\hline Konkurentsipõhine organisatsioon & Õppiv organisatsioon \\
\hline - Alluva roll on teenida organisatsiooni & $\begin{array}{l}\text { - Õpetajat nähakse organisatsiooni suurima } \\
\text { ressursina, eesmärk on õpetaja heaolu }\end{array}$ \\
\hline - Korraldused tulevad juhtkonnalt & $\begin{array}{l}\text { Õpetaja räägib kaasa organisatsiooni } \\
\text { arengus ning ennast puudutavates } \\
\text { küsimustes }\end{array}$ \\
\hline $\begin{array}{l}\text { Juhid motiveerivad väliste tasudega } \\
\text { (nt palk) või juhivad karistuste kaudu }\end{array}$ & $\begin{array}{l}\text { Tegutsema motiveerib tähenduslik töö, } \\
\text { kollegiaalsed suhted, vastastikune austus, } \\
\text { personaalsete ja kollektiivsete eesmärkide } \\
\text { saavutamine }\end{array}$ \\
\hline $\begin{array}{l}\text { - Rakendatakse „jaga ja valitse“ juhtimis- } \\
\text { stiili, töötajad tunnevad isolatsiooni }\end{array}$ & $\begin{array}{l}\text { - Organisatsioon toetab koostöövõrgustikke } \\
\text { ja suhteid }\end{array}$ \\
\hline • Uued õpetajad upuvad või ujuvad & $\begin{array}{l}\text { - Uusi õpetajaid toetatakse mentorsuhete } \\
\text { kaudu }\end{array}$ \\
\hline - Juhid hindavad sooritust ja vigu & • Õpitakse liikmete tagasisidest \\
\hline $\begin{array}{l}\text { - Tuleviku planeerimine on piiratud } \\
\text { juhtkonna tegevusega }\end{array}$ & $\begin{array}{l}\text { - Õpetajad kujundavad tulevikuplaane koos } \\
\text { juhtkonnaga }\end{array}$ \\
\hline
\end{tabular}


Õppivas organisatsioonis tähendab koostöine õpikultuur nii enda suutlikkust väljendada personaalset eesmärki kui ka jagatud ühist tulevikuvisiooni. Seevastu konkurentsipõhine organisatsioon ei toeta õppivale organisatsioonile omast koostöövõrgustikes tegutsemist, mille korral on oluline teadmiste ja kogemuste jagamine ning probleemide lahendamine (Wenger, 1998; Wenger, McDermott, \& Snyder, 2002).

Koostöise õpikultuuri kujunemist soodustavad mitmesugused tegurid. Nende hulka kuuluvad mittevõistlev keskkond, vastastikused usalduslikud suhted, tunnustamine, hoolivus ja võimalus eksida (Feys \& Devos, 2015; Kruse \& Louis, 2008). Koostöise õpikultuuriga organisatsioonides õpitakse koostöövõrgustikes ning selle tulemus avaldub ühistes uskumustes ja keelekasutuses. Ka Wengeri $(1998,2009)$ sotsiaalse õppimise käsituse kohaselt avaldub õppimine kui tegemine ja praktika viisis kõnelda ühistest eesmärkidest ja tegevustest. Õppimine kui kokkukuuluvus kogukonnaga ilmneb omakorda viisis kõnelda sotsiaalsetest suhetest, kus tegevus on tähenduslik ja väärib pingutust (ibid.).

Koostöise õpikultuuriga organisatsioonides on õpetajatel ühised eesmärgid, nad jagavad vastutust ja täidavad ühist ülesannet. Koostöise praktika juurdumiseks tuleb avada klassiruumi uks, olla valmis õppima ise ja õpetama teisi õpetajaid (Richardson \& Placier, 2001). Tähtis on kaaslaste mõistmine ja arusaam koostöö väärtusest, kuna individuaalsete eesmärkide teostamine sõltub ka teiste meeskonnaliikmete panusest (Carpenter et al., 2008; Hamilton, Sherman, \& Castelli, 2002). Seejuures teeb Datnow (2011) vahet väärtuslikul, produktiivsel ja meeldivana tajutud spontaansel koostööl ning administratiivsete korralduste kaudu õpetajaid koostööle kohustaval kollegiaalsusel. See tähendab, et õpikultuuri ei saa muuta institutsionaalselt ülevalt alla ega ka altpoolt üles, vaid sotsiaalsel interaktsioonil põhinevas üksikisikute ja rühmade koostoimes, võimestades kõiki osalisi (Biesta et al., 2015, 2017). Seetõttu peavad organisatsiooni liikmed olema muudatuste tegemisse kaasatud ja selleks võimestatud (Blue, Shove, Carmona, \& Kelly, 2016).

Eestis on käsitletud probleemina õpetajate ebapiisavat koostööd, kuid puuduvad uuringud selle kohta, kuidas koostöö tähendusi mõtestatakse, koostööd ja selle puudumist organisatsioonis kogetakse ning enda agentsust kirjeldatakse. Ka uuringus „Koostöö kutseõpetaja professionaalsust määrava tegurina“ on rõhutatud, et kvantitatiivne uurimisviis ei võimalda mõista, kuidas õpetajad enda autonoomiat töös mõtestavad ning kuidas see nende professionaalsust mõjutab (Sirk et al., 2017). Seetõttu on uurimuse eesmärk selgitada, millised on õpetajate koostöökultuuri kogemused. Artiklis keskendutakse järgmistele uurimisküsimustele. 
1. Mis diskursuste kaudu konstrueerivad õpetajad enda koostöise õpikultuuri kogemust individuaalsel, suhtlus- ja institutsionaalsel tasandil?

2. Kuidas väljendavad õpetajad enda agentsust?

\section{Empiiriline uurimus}

\section{Valim ja metoodika}

Sihipärase valimi moodustamiseks pöörduti 15 üldhariduskooli juhtide poole, kes osalesid kahel järjestikusel aastal üle-eestilises uuringus "Kooliuuring“ (2016, 2017). Koolijuhtidel paluti edastada palve uuringus osalemiseks kolmele eri vanuses, eri staažiga ja eri ainevaldkonna õpetajale. Intervjuud tehti 45 õpetajaga 15 Eesti üldhariduskoolist. Valimirühmades olid esindatud kõigi koolitüüpide (algkooli, põhikooli, gümnaasiumi, riigigümnaasiumi), eri suuruse ja asukohaga koolide (üheksa linnakooli, nelja linnalähedase maakooli ja kahe maakooli), eri kooliastmete ja valdkondade õpetajad. Uuringus osalejate keskmine vanus oli 42,4 aastat ( $\min 22$ ja max 65) ning tööstaaž 15,4 aastat (min 2 kuud, max 43 aastat).

\section{Andmete kogumine}

Andmeid koguti suulise poolstruktureeritud individuaalse intervjuuga, mis võimaldab esile tuua osalejate kogemusi, hoiakuid, arvamusi, suhtumist, tundeid ja teadmisi (vt Merriam \& Tisdell, 2015). Intervjuu alusena kasutatud küsimustik loodi koostöös haridusvaldkonna praktikute ja ekspertidega, kes kaasati uurimisprotsessi enne andmete kogumist. Sellise uurimisviisi (delfi meetodi) korral kogutakse ekspertide arvamusi ja püütakse ekspertide seas saavutada konsensus (Linstone \& Turoff, 1975).

Kuna delfi meetodi korral jääb osalejate soovitatav arv vahemikku 30-50 inimest, kuulus eksperdirühma 31 koolijuhti, õpetajat ja haridusametnikku, kes õppisid Tallinna Ülikooli haridusjuhtimise magistriõppes. Eksperdirühm kohtus neljal korral (märts-mai 2017) ning nendel kohtumistel, milles osales ka üks uurijatest, sõnastati eksperdirühma liikmete kogemustele toetudes esmalt õpetajate koostöövormid ja -tegevused. Seejärel tehti nende seast valik, välistades tegevused, millega enamik ekspertidest ei nõustunud, nt õppijate arengu koostöine toetamine, mida peeti õpetaja ametijuhendist lähtuvaks tööülesandeks. Küsimustiku sobivuse kontrollimiseks tegi iga eksperdirühma liige prooviintervjuu 1-2 enda valitud õpetajaga. Prooviintervjuude tulemuste analüüsi põhjal täpsustati küsimustiku väidete sõnastust. 
Eksperdirühma töö tulemuste põhjal lõid uurijad kolmeosalise küsimustiku, mis koosnes 34 väitest. Väited jagati küsimustiku osadesse koostöise õpikultuuri individuaalse, suhtlus- ja institutsionaalse tasandi tunnuste alusel (Euler, 2010; Feixas \& Zellweger, 2010):

1) individuaalsel tasandil esitati 5 väidet õpetaja hoiakute kohta, nt „Mulle meeldib, kui mu tunde külastatakse“, „Tegelikult on omaette tegutsemine tulemuslikum kui rühmas toimetamine“;

2) suhtlustasandil esitati 16 väidet valitseva suhtlusstiili kohta, nt „Õpetaja osaleb kooli arengut ja tulevikuplaane käsitlevates aruteludes“, „Õpetaja jagab teiste õpetajatega oma kogemusi ja parimaid praktikaid“;

3) institutsionaalsel tasandil esitati 13 väidet juhtkonna toetuse kohta, nt „Juhtkond tunnustab oma õpetajaid“, „Õppenädalasse on kavandatud ajaressurss õpetajate koostööks".

Uurijad tegid individuaalsed intervjuud valimisse kuuluva 45 õpetajaga vahemikus oktoober-detsember 2017 intervjueeritavate õpetajate koolides. Intervjuu käigus avas õpetaja iga väidet enda vabas sõnastuses, mille põhjal moodustus empiiriline materjal. Intervjuu ühe õpetajaga kestis umbes tund aega, intervjuu transkribeeriti sõna-sõnalt. Kõik 45 intervjuud kodeeriti numbritega tegemise järjekorras (ÕP1, ÕP2 jne).

\section{Diskursuseanalüüs andmeanalüïsi meetodina}

Õpetaja koostöökultuuri aluseks olev sotsiaalne interaktsioon hõlmab tähendusi, norme, ideoloogiat, oskusi, tegevusi, materiaalset keskkonda ja infrastruktuuri ning väljendub diskursiivselt suhete ja kommunikatsiooni kaudu (Shove, Pantzar, \& Watson, 2012). Sotsiaalset interaktsiooni käsitatakse uuringus üksikisikute ja rühmade koostoimena ning selle fookuses on interaktsioonipartneri tegevuse tõlgendamine ja sellele tähenduse omistamine (Vihalemm, Keller, \& Kiisel, 2015). Diskursust mõistetakse uuringus suhtlusviisina konkreetses sotsiaalses, kultuurilises, ajaloolises ja poliitilises situatsioonis (van Dijk, 2005).

Kriitiline diskursuseanalüüs võimaldab keeleliste valikute kaudu tekstides esile tuua ühiskondlikud kokkulepped, tähendused ja võimusuhted, mis sotsiaalses interaktsioonis avalduvad. Nimelt valitsevad igas kollektiivis kokkuleppelised diskursiivsed tavad, harjumuspärased keelekasutusviisid, kus keelekasutajad mõjutavad sotsiaalseid suhteid (Kasik, 2008). Üks olulisimaid kriitilise diskursuseanalüüsi autoreid Norman Fairclough $(1989,2005)$ on esitanud analüüsi raami, mis hõlmab tekstianalüüsi, interaktsiooni ja sotsiaalsete praktikate analüüsi. Kriitilise diskursuseanalüüsi abil uuritakse, milliseid identiteete, suhteid ja uskumisi ühiskonnas, organisatsioonis konstrueeritakse ning mis keelestruktuure selleks kasutatakse. Seetõttu võimaldab just diskursu- 
seanalüüs kirjeldada õpetajate kogetud õpikultuuri, mis väljendub kasutatavate väljendusviiside kombinatsioonides.

Sotsiaalsed suhted avalduvad tekstides lausetüüpide, kõneviiside, eituse ja sõnavara kaudu, väljendades kõneleja suhtumist ehk modaalsust (Kasik, 2008). Tegevused eeldavad tegijana esile toodud või siis varjatud inimesi ehk agente (van Leeuwen, 1996). Agentiivsus tähendab aktiivse osalise olemasolu suhtlussituatsioonis (EKG II, 1993). Agentiivsuse käsitlemine võimaldab uurida õpetaja tegutsejapositsiooni ehk agentsust organisatsioonis, kirjeldada õpetaja hoiakuid, suhteid teistega, suhtumist olukordadesse ja vastutuse võtmist, aga ka organisatsioonis valitsevaid võimusuhteid.

\section{Andmeanalüïs}

45 intervjuud analüüsiti intervjuude kaupa, tuginedes järgmistele analüüsietappidele.

1. Mõlemad uurijad lugesid 45 intervjuud eraldi läbi (lähilugemine) ning tegid esmase analüüsi. Seejärel vahetati analüüsimaterjali ja diskuteeriti selle üle, milliseid keeleanalüüsi võimalusi saab kasutada.

2. Mõlemad uurijad märgendasid teatud identiteete esindavate kõnelejate keelekasutusviisid. Sel moel eristusid keeleanalüüsi põhjal õpikultuure kirjeldavad peamised diskursused ja kujunesid õpetaja profiilid. Et vastata uurimisküsimusele, mis diskursuste kaudu konstrueerivad õpetajad enda koostöise õpikultuuri kogemust individuaalsel, suhtlus- ja institutsionaalsel tasandil, eristati diskursusi selle alusel, kuidas õpetajad suhestuvad koostööteemaga individuaalsel tasandil (ma arvan, et koos on ideed paremad vs. olen omaette tegutseja), kuidas nad räägivad suhtlustasandil kolleegidest ja organisatsiooni suhtlusstiilist (kõik on nagu üks meeskond vs. on õpetajad, kellega ei saa) ning mil moel väljendavad institutsionaalsel tasandil suhteid juhtkonnaga (on näha, et su tööst hoolitakse vs. keegi ei tunnusta). Selgitamaks, kuidas väljendavad õpetajad enda agentsust, analüüsiti, kas vastaja konstrueerib tähendusi aktiivse tegutseja positsioonilt (mind motiveerib vs. juhtkond surub peale ülesandeid), kas ta kasutab eitust (pole kuulnud, ma ei usu) ja kas ta näeb ressursse olukorra mõjutajana (julgeme teha vs. peame koostööd tegema).

3. Sarnaste õpetajate profiilide põhjal kujunesid välja aladiskursused. Kahe vastanduva diskursuse (koostöö- ja mittekoostöödiskursuse) vahele jääv diskursus eendus eelkõige inimestevahelise konkurentsi kaudu. Koostöödiskursuse alla asetusid 14 vastajat, kes kolme tasandi puhul kasutasid peamiselt jah-vormi ning kelle keelekasutuses väljendus aktiivne tegutsejapositsioon. Konkurentsidiskursuse alla paigutus 24 vastajat, kelle puhul 
eristus suhtlus- ja institutsionaalsel tasandil mingis olukorras koostöö puudumine ning kelle agentsus varieerus. Mittekoostöödiskursust esindasid 7 vastajat, aga kuna nad kasutasid kõigis kolmes dimensioonis rohkesti eitust, ei näinud ressursse tegutsemiseks ega väljendanud enda agentsust, on edaspidi nimetatud seda kategooriat võimestamata õpetaja diskursuseks. Tulemused on esitatud koostöö- ja konkurentsidiskursuse ning võimestamata õpetaja diskursuse alapeatükkides. Alapeatükid sisaldavad iseloomulikke näiteid individuaalse, suhtlus- ja institutsionaalse tasandi kohta, osutades, kuidas õpetajad konstrueerivad enda koostöökogemust ning kuidas väljendub agentsus.

\section{Tulemused}

\section{Koostöödiskursus}

Individuaalsel tasandil väljendab koostööd kogev õpetaja motiveeritust, ta on teadlik kooli visioonist ja ka enda eesmärkidest. Ôpetaja jagab uskumust, et koos on parem tegutseda ja ühiselt jõutakse paremate tulemusteni.

Mind motiveerib see, kui ma saan aru, et minu tööd on organisatsioonile vaja. (Õ4).

Meie kool liigub selles suunas, et tervikliku maailmapildi saamiseks tahetakse lõimida erinevad õppeained. (Õ6)

Ma arvan, et koos on ideed paremad ja tulemus rikastavam. (Õ27)

Suhtlustasandil kolleegidest rääkides väärtustab koostöökultuurist osa saav õpetaja info jagamist ja tegutsemisjulgust, üksteiselt õppimist, mis toimub vabatahtlikkuse alusel.

Meil on ka koostöökoosolekud, kus jagame üksteisele infot, kui oleme kuskil käinud. Räägime, mida uut oleme lugenud. Julgeme seda teha. (Õ17)

Kui keegi on head metoodikat õppinud, nt mingit programmi kasutama, leitakse aeg ja võimalus koolitamiseks. Vastastikku koolitamine on tavaline. (Õ3)

Meil toimuvad iganädalaselt nutivahetunnid. 1-2 õpetajat, kes on mõne hea IT-lahenduse leidnud, tutvustavad seda teistele. See on vabatahtlik. (Õ6)

Koostöödiskursuse kogemuste kirjeldamisel räägib õpetaja nooremate toetamisest, üksteise sütitamisest, meeskonnatundest ja kolleegide aktsepteerimisest. 
Väga noorele inimesele leitakse ka ainealane tugiisik. Me ei taha, et see oleks peale sunnitud. (Õ6)

Ideedega inimesed kutsuvad teisi kaasa. (Õ16)

Kõik on nagu üks meeskond, kellelegi ei vaadata viltu. (Õ11)

Õpetaja tunneb rahulolu tunnikülastuste üle, kuna tagasisidet kogetakse toetava ja lahenduskesksena. Koostöö puhul rõhutab õpetaja, et avatud uksed on osa õpikultuurist.

See on ka privileeg, kui keegi tahab minu tundi tulla. (Õ17)

Aastaid on meie koolis hea tava, et külastatakse kolleegide tunde, et saada ideid. (Õ6)

Ma annan tunde nii, et klassiuks on lahti. (Õ4)

Institutsionaalsel tasandil eendusid juhtkonna toetuse ja kaasamise teemad. Õpetaja tunneb, et on kooli juhtimisse ja arendustegevusse kaasatud, ning näeb selle kasu. Tal on võimalik valida töörühmi. Juhtkond panustab sellesse, et õpetajad saaksid soovi korral üksteiselt õppida.

Tulevikuplaane käsitlevad asjad räägitakse läbi nii, et iga õpetaja on kaasatud. (Õ27)

Töögruppide teemad mõeldakse välja koostöös. (Õ16)

Koolivaheajal on lisaks õppenõukogule mõttekojad. Erinevates sektsioonides räägitakse kooliüleselt, millised võiks olla järgmise aasta eesmärgid. (Õ6)

Kord aastas on nädal, kus õpetajad külastavad teiste tunde. Juhtkond on nt minu asemel tunnis. Sealt saame ideid. See on võimalus, mitte kohustus. (Õ16)

Koostöökultuuri korral on tagasiside põhjalik ning kogemus innustav ja tunnustav. Õpetajat avalikult ei kritiseerita. Vastajad väljendavad seisukohta, et juhtkond tunneb huvi õpetajate tegevuse vastu, toetab initsiatiivikust ja erinevaid lahenduskäike.

Juhtkonna tagasiside on innustav, maatasa tegemist pole. (Õ25)

See on argumenteeritud ja põhjalik tagasiside. On näha, et su tööst hoolitakse. (Õ16)

Õppealajuhataja küsib alati, kuidas mul tundidega läheb. (Õ34)

Ja ma tunnetan ka seda, et juhtkond toetab õpetajate hullumeelseid ideid. (Õ25) 
Koostöise diskursuse puhul kirjeldab õpetaja ennast aktiivse tegutsejana nii individuaalsel tasandil (mina arvan, mina mõtlen), suhtlustasandil (räägime, mida uut oleme lugenud; me suhtleme, julgeme) kui ka institutsionaalsel tasandil (ja ma tunnetan ka seda, et juhtkond toetab). Õpetaja kasutab koostööd väljendavaid tegusõnu (teevad, arutavad, jagavad). Koostöökogemus tähendab õpetaja jaoks eneseteostust ja tähenduslikku tööd (mind motiveerib), koos õppimist ja katsetamist, kooli arendamist. Osalejad saavad valida tegevusi ja töörühmi ning tunnevad kooli arengu eest vastutust. Juhtidest rääkides väljendab vastaja, et teda kaasatakse otsustusprotsessidesse (tulevikuplaane käsitlevad asjad räägitakse läbi nii, et iga õpetaja on kaasatud), temast hoolitakse (on näha, et su tööst hoolitakse) ning talle saab osaks tunnustus (juhtkonna tagasiside on innustav).

\section{Konkurentsidiskursus}

Individuaalsel tasandil näeb vastaja konkurentsidiskursuse puhul ennast aktiivse tegutsejana: ta kasutab aktiivsele tegutsemisele osutavaid verbe (teen, käin, tegelen, jagan) ja väljendab soovi tegutseda. Erinevalt koostöödiskursusest peab aga õpetaja üksi tegutsemist tulemuslikumaks ja leiab sellele ka kinnitust.

Mina teen, käin selgitamas, tegelen, jagan, mina sooviks vahel rohkem teha.

(Õ15)

Vahel on lihtsam asju üksi teha ja tulemus on olnud väga hea (mitte ainult minu hinnangu põhjal, vaid ka tulnud tagasisidena). (Õ44)

Suhtlustasandil eendusid vastuolulised diskursused. Leidub selliseid õpetajaid, kes näevad kolleegides koostööpartnereid. Õpetaja kogeb õpikultuuri selle kaudu, et on enda ja kolleegide suhtes hästi meelestatud, millest annavad tunnistust koostööle osutavad tegusõnad tullakse, näidatakse ja osalevad. Samas viitab õpetaja vähesele jagamiskultuurile.

Tullakse ja näidatakse, keegi kiivalt midagi enda teada ei hoia. (Õ13)

Mul on endal ka hea tunne, kui saan kellelegi öelda, et ta tegi midagi hästi. (Õ21)

Meil on väga nutikad õpetajad, osalevad igal pool. Aga ei presenteeri seda nii palju. (Õ19)

Pigem igaüks ajab oma rida. (Õ32)

Vaatlusalust diskursust iseloomustab asjaolu, et õpetaja tunneb puudust võrgustikust, kolleegi toetusest ja järelkasvust. 
Tunnen teinekord puudust, et mul pole omaealist õpetajat. (Õ15)

Tunnen puudust, et ma olen ainuke vene keele õpetaja. (Õ20)

Juba väga ammu pole uusi inimesi olnud. (Õ43)

Õpetajad kogevad, et ülekoormus, ajapuudus, ainekesksus ja riigieksamiteks valmistumine takistavad koostööd.

See kõik [koostööprojektid] käib millegi arvelt, ma ei taha ainetunde ära anda. (Õ15)

Mul on kitsas eriala, õpetan riigieksami ainet. Mul on kiire. (Õ23)

Samas iseloomustab konkurentsidiskursust asjaolu, et õpetaja tunneb töökollektiivis kellegi vastasseisu, näeb mingit rühma koostöö takistajana. Takistus võib johtuda ka elukohast vms.

Ja siis on raudvara, kes ei ole valmis grammigi oma nõudmistest tagasi astuma. Kui oleks minu teha, siis tuleks need õpetajad välja vahetada. (Õ10)

Need, kes käivad linnast, annavad koolis lihtsalt tundi. Oma parimaski tahtmises ei kuulu nad siia kogukonda. (Õ41)

Kolleegide tundide vaatlemise vastu õpetaja huvi ei tunne. Vaatlema mineku takistusena nimetab ta huvi- ja infopuudust. Õpetaja ei väljenda end agentsena, vaid kasutab sõna peab või eitust.

Õpetaja peab käima tundides, peab tegema analüüsi ja peab andma tagasisidet. (Õ13)

Mul on ükskõik, kas keegi käib tundides. (Õ20)

Pole kaasa rääkinud, ei tea, ei oska öelda, ei osale. Ma ei tea sellest midagi, pannakse kusagile välja, aga ei tea kuhu. (Õ45)

Institutsionaalsel tasandil eendus juhtkonnale vastandumise diskursus, mille korral kasutab vastaja sõnu kohustuslik või sunnib ning ta ei näe tegevustel tähendust.

Juhtkond sunnib meid koostööd tegema, annab korraldusi. (Õ19)

Kohustus on olla kella neljani koolis. (Õ31)

Õpetaja ei pälvi juhtkonnalt piisavalt tunnustust. Pigem saab ta kritiseeriva tagasiside osaliseks ning tunneb majasisest konkurentsi. 
Kui meelde tuletada, siis tunnustavad. Kas raske on öelda või? (Õ21)

Kipub minema negatiivseks, tuuakse välja plussid ja miinused isikute või ainesektsioonide järgi. (Õ2)

Konkurentsidiskursuse korral väljendab õpetaja individuaalsel tasandil agentsust (mina teen, käin selgitamas, tegelen, jagan). Suhtlustasandil räägib õpetaja (osast) kolleegidest kui aktiivsetest tegutsejatest (meil on väga nutikad õpetajad, nad osalevad igal pool). Koostööd kogeva rühmaga võrreldes kasutavad vastajad rohkem eitust ning väljendeid, mis viitavad koostöö kohustuslikkusele ja agentsuse puudumisele (sunniti, peab olema). Õpetaja ei näe kõigi kolleegide panust (ópetajaid, kellega ei saa), vaid ta osutab takistustele, ressursside puudumisele (mul on kiire). Võrreldes eelmise rühmaga ei väljenda õpetaja ei personaalset ega kollektiivset visiooni. Institutsionaalsel tasandil rõhutab ta koostöö sunduslikkust (juhtkond sunnib meid koostööd tegema). Juhtkonnaga seoses mainitakse vähest tunnustamist (eestlastel ei ole kombeks tunnustada).

\section{Võimestamata õpetaja diskursus}

Individuaalsel tasandil väljendub võimestamata õpetaja diskursus selles, et õpetaja tunneb end eri põhjustel üksikuna ning teda valdab teadmatus enda ja kaaslaste suhtes. Tegevuse takistusena näeb ta info puudumist. Samuti puudub õpetajal arusaam enda ja kooli kui organisatsiooni eesmärkidest. Vastaja mainib vähenenud motivatsiooni, tähenduse puudumist. Keelekasutuses esineb palju eitust. Diskursust iseloomustab see, et õpetajad tegutsevad omaette.

Ma ei oska kaasa räk̈kida. Ma ei oskagi öelda, milles see probleem võiks olla. (Õ9)

Varem tegin rohkem, entusiasm rauges, ei saanud midagi vastu. (Õ14)

See, mis on, [on] tundunud nõme, uus tundub veelgi nõmedam. (Õ12)

Olen omaette tegutseja. Paljud kolleegid on pigem omaette. (Õ18)

Nagu individuaalsel tasandil, kasutasid vastajad ka suhtlustasandil ei-sõnumeid. Õpetaja ei tunne ennast meeskonna osana, on teistest eraldi, ei suhtle kõigi kolleegidega. Ühe peamise koostegevusena nimetab õpetaja kogemuse jagamist, aga see ei paku talle tuge. Õpetaja peab koosõpetamist häirivaks. Õpilastest räägib ta verbi haldama kasutades.

Me oleme väga killustunud, oleme oma rakukestes. (Õ14)

Pole kokkupuudet ülejäänud õpetajatega, ei tunne end kooli meeskonna osana. (Õ28) 
Kui keegi on midagi teinud, siis teine täiendab. Või otsib sealt vigu. (Õ8)

Kohvitassi taga räägivad, kuidas neil tunnis on. Kuidas nad õpilasi haldavad. (Õ24)

Kõik õpetajad on indiviidid ja erinevad. Mulle tundub, et see [koosõpetamine] võib olla raske ja häiriv. (Õ12)

Tundide vaatlemine on õpetaja jaoks kohustuslik ning tekitab ebakindlust ja stressi. Sügava tähenduse puudumise tõttu ei tunne ta selle vastu huvi.

Tunnivaatlus tekitab põhjendamatut ärevust ja stressi. (Õ 14)

Poolaasta peale on kohustus käia teiste tundides. (Õ8)

Õpetaja ei taju end organisatsiooni ega kogukonna liikmena, väljendab agentsuse puudumist: olen siia sattunud. Õpetaja ei panusta kooli arengusse.

Ma ei ole veel aru saanud, mida humanitaaria inimesed teevad. Kooli arengut tervikuna puudutavad arutelud - seda pole märganud. (Õ24)

Kohalik kogukond jääb minu jaoks võõraks - olen siia sattunud. (Õ18)

Institutsionaalsel tasandil ei tunne õpetaja juhtkonna toetust-tunnustust ega näe, et tema tööd väärtustataks. Ta ei usu arenguvestlustesse, ei saa ega tahagi saada tagasisidet, kuna ei näe selle kasulikkust.

Arenguvestlustele kutsutakse teatud õpetajaid. Ma ei taha minna, see on mõttetu. (Õ12)

Kui töölt ära lähed, siis antakse lilled. Kui teed siin tööd, siis keegi ei tunnusta. (Õ28)

Õpetajale saab osaks hierarhiline juhtimisstiil. Juhtkonna tegevus ja kogemuste jagamine pole õpetajale tähenduslikud. Koostöö on õpetaja jaoks pealesurutud tegevus.

Juhtkond surub peale ülesandeid, mida peab koostöös tegema. (Õ28)

Juhtkonna poolt korraldatud koosolekud, kus jagatakse mingeid kogemusi. (Õ12)

Võimestamata õpetaja keelekasutust iseloomustavad individuaalsel tasandil rohked ei-sõnumid (ei näe, ei tea, ei ole kuulnud, ei teinud, ei oska, ei ole aru saanud). Vastaja toob negatiivsena esile ressursside (aja, huvi vms) puudumise. Võimestamata õpetaja ei oma infot ega usu koostöösse, ei väljenda enda ega 
ühist arusaama eesmärkidest. Õpetaja ei pea end agentseks ehk organisatsioonis aktiivseks osalejaks. Suhtlustasandil ei näe ta ka kolleegides ressurssi (paljud kolleegid on pigem omaette). Seetôttu nimetab ta ühiste tegevustena peamiselt juhtkonna ette nähtud tegevusi, kasutades mitte-koostööle osutavaid keelelisi väljendeid (kohustus käia, kästi, juhtkond surub peale, peab koostöös tegema). Võimestamata õpetaja ei taju juhtkonna toetust (kui teed siin tööd, siis keegi ei tunnusta).

\section{Arutelu}

Uurimuse eesmärk on selgitada, millised on õpetajate koostöökultuuri kogemused. Uurimistulemused näitavad, et õpetajate kogemused on erinevad: muude diskursuste hulgast eendusid koostöö- ja konkurentsidiskursus ning võimestamata õpetaja diskursus. Koostöödiskursuse näol sai kinnitust, et mittevõistlev keskkond, usalduslikud suhted, tunnustamine, hoolivus, võimalus eksida, üksteiselt õppimine ja klassiruumi ukse avamine soodustavad koostöist õpikultuuri (Feys \& Devos, 2015; Kruse \& Louis, 2008; Richardson \& Placier, 2001). Koostöises keskkonnas töötavad õpetajad väärtustavad üksteise toetamist, riskimist, katsetamist, juhtkonna usaldust, toetust ja julgustamist. Õpetajad võtavad oma tegevuse eest vastutuse, kui mõistavad kaugemaid ühiseid eesmärke. Ühtlasi toetavad õpetajate antud vastused TALISe uuringu väidet, mille põhjal teevad õpetajad, kes kasutavad rohkem võimalusi enesetäiendamiseks, omavahel ka rohkem koostööd ja vastupidi (Loogma, Ruus, Talts, \& Poom-Valickis, 2009). Samuti leidis koostöödiskursuse puhul toetust Sirgi jt (2017) uuringu järeldus, et üksteist toetavad kolleegid arendavad ennast enam ka professionaalselt.

Agentsuse analüüsist ilmneb õpetaja varieeruv tegutsejapositsioon organisatsioonis: kui koostöödiskursuses on õpetaja agentsus väljendunud igal tasandil ja konkurentsidiskursuses õpetajate agentsus varieerub, siis võimestamata õpetajate agentsus on väga piiratud. Seejuures on õpetaja agentsus tihedalt seotud institutsionaalsel tasandil juhtkonna tegevusega: võimestamata õpetajad, kes ei koge juhtkonna toetust ja tunnustust, ei võta organisatsioonis ka tegutsejapositsiooni. Kui koostöödiskursuse puhul ilmnes spontaanse koostöö tunnuseid, siis konkurentsidiskursuse ja võimestamata õpetaja diskursuse puhul võis täheldada administratiivsetest korraldustest tulenevat kollegiaalsust (vt ka Datnow, 2011).

Koostöödiskursus ühtib õppiva organisatsiooni tunnustega (tabel 1), mille korral nähakse ideede jagamist professionaalse muutumise osana ning õpetajad tunnevad vastutust enda ja oma kooli arengu eest. Konkurentsidiskursus ja võimestamata õpetaja diskursus ühtivad konkurentsipõhise organisatsiooni 
tunnustega: õpetajad tajuvad vastutust enda klassiruumis toimuva, aga mitte kooli arengu eest (tabel 1), korraldused tulevad ülevalt, töötajad tunnevad end isoleerituna ning tuleviku planeerimine on piiratud juhtkonna tegevusega (tabel 2). Ka ühest varasemast Eestis tehtud uuringust, kus selgitati klassiõpetajate arusaamu õppivast organisatsioonist, on ilmnenud, et õpetajad kirjeldavad põhjalikumalt küll isiklikku, aga samas tagasihoidlikumalt ühist visiooni, meeskondlikku õppimist organisatsiooni tasandil (Uibu, Kaseorg, \& Kink, 2016), mis toetavad praeguse uuringu konkurentsidiskursusega ja võimestamata õpetaja diskursusega seotud tulemusi. Seejuures väljendusid koostöödiskursuse korral õpetajate keelekasutuses selgelt Wengeri $(1998,2009)$ sotsiaalse õppimise käsituse kesksed tähendused, kuid konkurentsidiskursuse puhul rõhutati, et kõik õpetajad ei kuulu kogukonda, ning võimestamata õpetaja diskursuse puhul leiti, et vastaja ei taju end ise kogukonna liikmena.

Praeguse uuringu põhjal leidsid kinnitust kutseõpetajate koostöö uuringu (Sirk et al., 2017) tulemused, mille kohaselt soodustab laiem koostöö positiivsemat suhtumist töösse, toetades muutuste mõtestamist ja omaksvõttu. Kuna kõik uuringus osalenud õpetajad pidasid oluliseks võimalust kaasa rääkida kooli juhtimist puudutavates küsimustes, siis pakub just see potentsiaali koostöö laienemiseks (ibid.). Üks muutust loov tegevus on ka õpetajate kaasamine võrgustikesse eesmärgiga pakkuda neile võimalust osaleda kooli tuleviku kujundamises (Erss \& Kalmus, 2018).

Koostöökogemuste uurimine poolstruktureeritud intervjuu kaudu hõlmas koostöö eri aspekte, kuid küsimused võisid osalejaid suunata andma väljakujunenud kokkulepete kohaseid vastuseid. Andmeanalüüsi tulemused võimaldavad teha järeldusi domineerivate diskursuste kohta, küll aga ei saa nende põhjal järeldada, mis mahus neid diskursusi Eesti koolides esineb. Kui Sarve (2008) uuringu põhjal oli õppiva organisatsiooni tüüpi koole Eestis ligikaudu neljandik ning Salumaa (2007) uuringu põhjal pole ligi pooled õpetajad valmis võtma vastutust muudatuste eest, siis vajaksid ka need olulised väited tulevikus lisauuringuid. Lisaks näitab Sirgi jt (2017) uuring, et meesõpetajad ja vene kutsekoolide õpetajad osalevad koostöövõrgustikes vähem, kuid see võib olla tingitud valimirühma soolisest koosseisust, kuna valimisse kuulus ainult kolm meesõpetajat. Seetõttu tuleks edaspidi uurida eraldi ka meesõpetajate koostöökogemust. Samuti on oluline selgitada välja vene õppekeelega koolide õpetajate koostöökogemus.

Siinse uurimuse peamine panus seisneb organisatsiooni koostöise õpikultuuri aluseks olevate diskursiivsete tavade ja keelekasutuse kirjeldamises. Muutuste toetamiseks tuleb koostöise arendustegevuse ja tegevuste eesmärgistamise kaudu panna alus uuele ühisele tähenduslikule keelekasutusele, mis võimestab osalejaid ja toetab uusi uskumusi. Kuna koostöine kultuur 
kasvatab õpetajate eneseusku ja julgust olukordi juhtida (Kohm \& Nance, 2009) ning võimestamine toetab õpetaja enesetõhusust, pühendumist ja motivatsiooni (Luechauer \& Shulman, 1992), siis on kooli juhtkonna üks ülesandeid leida võimalusi, kuidas toetada võimestavat õpikultuuri. Sõltub ju õpetajate koostöö paljuski koolijuhtimisest (Forte \& Flores, 2014; TALIS, 2008; Vangrieken et al., 2015). Võttes aluseks koostöödiskursuses eristunud õpetajate kogemused, on alljärgnevalt esitatud koolide juhtkonnale mõningaid soovitusi kooli õpikultuuri toetamiseks.

1. Õpetajat motiveerib võimalus panustada kooli arendustegevusse, kui ta saab luua kollektiivset visiooni ning valida rolle, teemasid, töörühmi ja tegutsemisviise. Tähtis on koostöövajadust põhjendada, tegevusi üheskoos mõtestada ja selleks aega võtta.

2. Kollegiaalne õppimine ja üksteise toetamine eri koostöövõrgustikes loovad jagamiskultuuri, vältides võistlusmomenti õpetajate vahel. Tunnivaatlused ja lahenduskeskse tagasiside andmine edendavad õpetajatevahelist usaldust.

3. Süsteemsus ja järjepidevus kogemuste jagamisel ning üksteiselt õppimisel, mis toimub koostööd soodustavas füüsilises keskkonnas ühiselt planeeritud ajal (soovitatavalt tööpäeva keskel), võimestavad õpetajaid muutustega kohanemisel ja uuenduste rakendamisel.

4. Ühine infoväli, kus on arvestatud õpetajate vajaduste, võimaluste ja harjumustega (meilid, teadetetahvlid, suusõnaline info jne), soodustab koostööd ja kaasatust.

5. Õpetajate ühiselt korraldatud regulaarsed koostegutsemise traditsioonid, sh kogukondlike, spordi- ja kultuuriürituste korraldamine, suurendavad oluliselt kaasatus- ja kuuluvustunnet.

6. Õpetajate süsteemne võimestamine suurendab nende enesetõhusust. Eksimishirmu puudumisel on õpetajad julgemad ja täis tahet uusi meetodeid ja lahendusi kriitiliselt arendama ning katsetama.

7. Juhtkonnapoolne õpetajate toetamine, innustamine, panuse, edusammude ja pingutuste märkamine, tunnustamine eri viisidel ning pidev tagasiside andmine suurendavad tööga rahulolu.

\section{Tänusõnad}

Autorid tänavad uuringus osalemise eest koole ja õpetajad ning väärt nõuannete eest Mati Heidmetsa, Halliki Põldat, Maria Erssi ja Klemen Slabinat. 


\section{Kasutatud kirjandus}

Biesta, G., Priestley, M., \& Robinson, S. (2015). Teacher agency: An ecological approach. Teachers and Teaching, 21(6), 624-640. https://doi.org/10.1080/13540602.2015.1044325

Biesta, G., Priestley, M., \& Robinson, S. (2017). Talking about education: Exploring the significance of teacher agency. Journal of Curriculum Studies, 49(1), 38-54. https://doi.org/10.1080/00220272.2016.1205143

Blue, S., Shove, E., Carmona, C., \& Kelly, M. P. (2016). Theories of practice and public health: Understanding (un)healthy practices. Critical Public Health, 26(1), 36-50. https://doi.org/10.1080/09581596.2014.980396

Brouwer, P., Brekelmans, M., Nieuwenhuis, L., \& Simons, R.-J. (2012). Communities of practice in the school workplace. Journal of Educational Administration, 50(3), 346-364. https://doi.org/10.1108/09578231211223347

Carpenter, S., Fortune, J. L., Delugach, H. S., Etzkom, L. H., Utley, D. R., Farrington, P. A., \& Virani, S. (2008). Studying team shared mental models. In P. J. Ågerfalk, H. Delugach, \& M. Lind (Eds.), Proceedings of the 3rd International Conference on the Pragmatic Web: Innovating the interactive society (pp. 41-48). New York: ACM. https://doi.org/10.1145/1479190.1479197

Collinson, V., \& Fedoruk Cook, T. (2007). Organizational learning: Improving learning, teaching, and leading in school systems. Thousand Oaks, London, New Delhi: Sage Publications.

Cross, R., Davis, S., \& O’Neil, I. (2017). Health communication: Theoretical and critical perspectives. Cambridge: Polity Press.

Daly, A. J., Moolenaar, N. M., Bolivar, J. M., \& Burke, P. (2010). Relationships in reform: The role of teachers' social networks. Journal of Educational Administration, 48(3), 359-391, https://doi.org/10.1108/09578231011041062

Datnow, A. (2011). Collaboration and contrived collegiality: Revisiting Hargreaves in the age of accountability. Journal of Educational Change, 12(2), 147-158. https://doi.org/10.1007/s10833-011-9154-1

Eesti elukestva õppe strateegia 2020 (2014). Tartu: Haridus- ja Teadusministeerium. Külastatud aadressil https://www.hm.ee/sites/default/files/strateegia2020.pdf.

EKG II = Erelt, M., Kasik, R., Metslang, H., Rajandi, H., Ross, K., ... Vare, S. (1993). Eesti keele grammatika II. Süntaks. Tallinn: Eesti Teaduste Akadeemia Keele ja Kirjanduse Instituut.

Erss, M., \& Kalmus, V. (2018). Discourses of teacher autonomy and the role of teachers in Estonian, Finnish and Bavarian teachers' newspapers in 1991-2010. Teaching and Teacher Education, 76, 95-105. https://doi.org/10.1016/j.tate.2018.08.003

Euler, D. (2010). Shaping learning cultures: A strategic challenge for universities. In U.-D. Ehlers \& D. Shenkenberg (Eds.), Changing cultures in higher education (pp. 75-84). Heidelberg, Dordrecht, London, New York: Springer. https://doi.org/10.1007/978-3-642-03582-1_7

Fairclough, N. (1989). Language and power. Edinburgh: Pearson Education.

Fairclough, N. (2005). Critical discourse analysis in trans-disciplinary research on social change: Transition, re-scaling, poverty and social inclusion. Lodz Paper in Pragmatics, 1, 37-58. 
Feixas, M., \& Zellweger, F. (2010). Faculty development in context: Changing learning cultures in higher education. In U.-D. Ehlers \& D. Schneckenberg (Eds.), Changing cultures in higher education (pp. 85-102). Heidelberg, Dordrecht, London, New York: Springer. https://doi.org/10.1007/978-3-642-03582-1_7

Fejes, A. (2008). Historicizing the lifelong learner: Governmentality and neoliberal rule. In A. Fejes \& K. Nicoll (Eds.), Foucault and lifelong learning (pp. 87-99). London: Routledge.

Feys, E., \& Devos, G. (2015). What comes out of incentivized collaboration: A qualitative analysis of eight Flemish school networks. Educational Management Administration \& Leadership, 43(5), 738-754. https://doi.org/10.1177/1741143214535738

Forte, M. A., \& Flores, A. M. (2014). Teacher collaboration and professional development in the workplace: A study of Portuguese teachers. European Journal of Teacher Education, 37(1), 91-105. https://doi.org/10.1080/02619768.2013.763791

Fullan, M. (2009). Large-scale reforms comes of age. Journal of Educational Change, 10(2), 101-113. https://doi.org/10.1007/s10833-009-9108-Z

Hamilton, D. L., Sherman, S. J., \& Castelli, L. (2002). A group by any other name The role of entitativity in group perception. European Review of Social Psychology, 12(1), 139-166. https://doi.org/10.1080/14792772143000049

Hargreaves, A. (2006). Four ages of professionalism and professional learning. In H. Lauder, P. Brown, J.-A. Dillabough, \& A. H. Halsey (Eds.), Education, globalization, and social change (pp. 672-691). Oxford: Oxford University Press.

Hord, S. M. (1997). Professional learning communities: Communities of continuous inquiry and improvement. Austin: Southwest Educational Development Laboratory. Retrieved from http://www.sedl.org/pubs/change34/plc-cha34.pdf.

Johns-Shepherd, L., \& Gowing, E. (2007). Beyond the classroom door, beyond the school gates: The imperative for school-to-school networks for professional learning. In J. Pickering, C. Daly, \& N. Pachler (Eds.), New designs for teachers' professional learning (pp. 116-132). London: University of London.

Kasik, R. (2008). Meediatekstide analüüs: eesmärgid ja metoodika. R. Kasik (toim), Tekstid ja taustad V (lk 10-43). Tartu: Tartu Ülikooli Kirjastus.

Kikoski, C. K., \& Kikoski, J. F. (2004). The inquiring organization: Tacit knowledge, conversation, and knowledge creation: Skills for 21st-century organizations. Praeger: Westport.

Kohm, B., \& Nance, B. (2009). Creating collaborative cultures. Educational Leadership, 67(2), 67-72. Retrieved from http://pdo.ascd.org/LMSCourses/PD13OC010M/ media/Leading_Prof_Learning_M4_Reading301.pdf.

Kruse, S. D., \& Louis, K. S. (2008). Building strong school cultures: A guide to leading change. Joint Publication with the American Association of School Administrators (AASA).

Lepik, M., Loogma, K., \& Talts, L. (2013). Õpetajakutse transformatsioon ühiskonnas: toimetulekustrateegiad, pedagoogilised uskumused ning tööidentiteet. E. Krull et al. (toim), Opetajate professionaalne areng ja selle toetamine (lk 227234). Tartu: Eesti Ülikoolide Kirjastus.

Linstone, H. A., \& Turoff, M. (Eds.) (1975). The delphi method: Techniques and applications. Reading: Addison-Wesley. 
Loogma, K., Ruus, V-R., Talts, L., \& Poom-Valickis, K. (2009). Õpetaja professionaalsus ning tõhusama õpetamis- ja óppimiskeskkonna loomine: OECD rahvusvahelise õpetamise ja õppimise uuringu TALIS tulemused. Tallinn: Tallinna Ülikooli haridusuuringute keskus. Külastatud aadressil https://www.hm.ee/sites/default/files/talis2008.pdf.

Loogma, K., Tafel-Viia, K., \& Ümarik, M. (2012). Social innovation: Three approaches. ZSI Discussion Paper, Nr 24. Innovating Innovation by Research - 100 years after Schumpeter.

Luechauer, D. L., \& Shulman, G. M. (1992). Moving from bureaucracy to empowerment: Shifting paradigms to practice what we preach in class. Paper presented at the Annual Midwest Academy of Management, St. Charles. Retrieved from https://eric.ed.gov/?id=ED360666.

Merriam, S. B., \& Tisdell, E. J. (2015). Qualitative research: A guide to design and implementation (4th ed.). San Francisco: Josey-Bass.

Preskill, H., \& Torres, R. T. (1999). Evaluative inquiry for learning in organizations. Thousand Oaks: Sage. https://doi.org/10.4135/9781452231488

Põlda, H., \& Aava, K. (2016). Muutunud õpikäsituse keeleline konstrueerimine. Eesti Rakenduslingvistika Ühingu aastaraamat, 12, 201-217. https://doi.org/10.5128/ERYa12.12

Richardson, V., \& Placier, P. (2001). Teacher change. In V. Richardson (Ed.), Handbook of research on teacher education (pp. 905-947). Washington: AERA.

Ruus, V-R. (2010). Õpetajakutse mitmetasandiline ja -dimensiooniline mudel ning strateegilised sõlmpunktid. E-S. Sarv \& V-R. Ruus (toim), Õpetaja esmaharidus. Olukord ja probleemid 21. sajandi algul (lk 7-35). Tallinn: Tallinna Ülikool. Külastatud aadressil http://dspace.ut.ee/bitstream/handle/10062/40590/Archimedes_ opetajaharidus.pdf? sequence $=1$ \&isAllowed $=\mathrm{y}$.

Salumaa, T. (2007). Representation of organizational culture in the process of change by Estonian teachers (Doctoral dissertation). Tallinn: Tallinna University.

Sarason, S. B. (1990). The predictable failure of educational reforms. San Fransisco: Jossey-Bass.

Sarv, E-S. (2008). Õpetaja ja kool õpilase arengu toetajana. Õpetaja enesest ja koolist. Tallinn: Tallinna Ülikool.

Scribner, J. P., Sawyer, R. K., Watson, S. T., \& Myers, V. L. (2007). Teacher teams and distributed leadership: A study of group discourse and collaboration. Educational Administration Quarterly, 43(1), 67-100. https://doi.org/10.1177/0013161X06293631

Senge, P. M., Cambron-McCabe, N., Lucas, T., Smith, B., \& Dutton, J. (2009). Õppiv kool. Tartu: Atlex.

Senge, P., Kleiner, A., Roberts, C., Ross, R., \& Smith, B. (2014). The fifth discipline fieldbook: Strategies and tools for building a learning organization. New York et al.: Doubleday.

Shove, E., Pantzar, M., \& Watson, M. (2012). The dynamics of social practice: Everyday life and how it changes. London: Sage.

Sirk, M., Ümarik, M., Loogma, K., \& Niglas, K. (2017). Koostöö kutseõpetaja professionaalsust määrava tegurina. Eesti Haridusteaduste Ajakiri, 5(2), 80-105. https://doi.org/10.12697/eha.2017.5.2.04 
Spring, J. (2004). How educational ideologies are shaping global society: Intergovernmental organizations, NGOs, and the decline of the nation-state. New Jersey: Lawrence.

TALIS 2008 = Loogma, K., Ruus, V. R., Talts, L., \& Poom-Valickis, K. (2009). Õpetaja professionaalsus ning tõhusama õpetamis- ja õppimiskeskkonna loomine. OECD rahvusvahelise õpetamise ja õppimise uuringu TALIS tulemused. Tallinn: Tallinna Ülikooli haridusuuringute keskus.

TALIS 2013 = Übius, Ü., Kall, K., Loogma, K., \& Ümarik, M. (2014). Rahvusvaheline vaade ópetamisele ja óppimisele. OECD rahvusvahelise ópetamise ja óppimise uuringu TALIS 2013 tulemused. Tallinn: SA Innove.

Timoštšuk, I., Ugaste, A., \& Mets-Alunurm, K. (2018). Õpetajate õppimiskogemused neoliberaalsete haridusmuutuste taustal. Eesti Haridusteaduste Ajakiri, 6(1), 77-101. https://doi.org/10.12697/eha.2018.6.1.04

Uibu, K., Kaseorg, M., \& Kink, T. (2016). Klassiõpetajate arusaamad õppiva organisatsiooni juhtimise distsipliinidest. Eesti Haridusteaduste Ajakiri, 4(1), 58-91. https://doi.org/10.12697/eha.2016.4.1.03

Van Dijk, T. A. (2005). Ideoloogia. Multidistsiplinaarne käsitlus. Tartu: Tartu Ülikooli Kirjastus.

Van Leeuwen, T. (1996). The representation of social actors. In C. R. CaldasCoulthard \& M. Coulthard (Eds.), Texts and practices: Readings in critical discourse analysis (pp. 32-70). London: Routledge.

Vangrieken, K., Dochy, F., Raes, E., \& Kyndt, E. (2015). Teacher collaboration: A systematic review. Educational Research Review, 15, 17-40.

https://doi.org/10.1016/j.edurev.2015.04.002

Vangrieken, K., Grosemans, I., Dochy, F., \& Kyndt, E. (2017). Teacher autonomy and collaboration: A paradox? Conceptualising and measuring teachers' autonomy and collaborative attitude. Teaching and Teacher Education, 67, 302-315. https://doi.org/10.1016/j.tate.2017.06.021

Vihalemm, T., Keller, M., \& Kiisel, M. (2015). From intervention to social change: A guide to reshaping everyday practices. London: Routledge.

Wenger, E. (1998). Communities of practice: Learning, meaning, and identity. Cambridge: Cambridge University Press.

Wenger, E. (2009). A social theory of learning. In K. Illeris (Ed.), Contemporary theories of learning (4th ed., pp. 209-218). London: Routledge.

Wenger, E., McDermott, R. A., \& Snyder, W. (2002). Cultivating communities of practice: A guide to managing knowledge. Boston: Harvard Business School Press. 


\title{
Teachers' experiences of collaborative learning culture based on examples from Estonian general education schools
}

\author{
Pille Slabina $^{a 1}$, Katrin Aava ${ }^{\mathrm{b}}$ \\ a School of Educational Sciences, Tallinn University \\ ${ }^{b}$ Baltic Film, Media, Arts and Communication School, Tallinn University
}

\begin{abstract}
Summary
The learning organisation is characterised by collaborative development, in which both teachers and management together form a plan for the future. People are motivated by meaningful work and self-realisation (Senge et al., 2014). The learning culture includes an individual, communication, and institutional dimension (Euler, 2010). In order to understand the organisation's learning culture, the study relies on the theory of social practices, according to which innovations are done collaboratively within social networks (Shove et al., 2012). Accordingly, social interactions are understood as interactions between individuals and groups, with an important role in assigning meaning to the activities of the interaction partner (Vihalemm et al., 2015). A discourse analysis of these meanings allows describing how participants in the organisation experience learning culture, and seeing obstacles and resources to support learning culture.

The purpose of the study is to discover how teachers construct their collaborative experiences through social interactions and find out how far they perceive themselves as agents. The goal is to describe the existing collaborative practices. Additionally, we aim, relying on the results of the analysis, to suggest how to support collaborative culture in schools, and to empower teachers. We focus on the following research questions: Through which discourses do teachers make collaborative learning experience meaningful at individual, communication and institutional levels? How do respondents express their agency?

The sample consists of 45 teachers from 15 Estonian general education schools. We carried out the data collection through a semi-structured oral individual interview, based on the questionnaire mapping teachers' collaborative experiences. The questionnaire consisted of 3 parts and 34 statements. Since
\end{abstract}

School of Educational Sciences, Tallinn University, Narva mnt 25, 10120 Tallinn, Estonia; pille.slabina@tlu.ee 
teachers' general attitudes towards collaboration significantly influence the contribution of teachers to collaborative activities (Vangrieken et al., 2017), individual level statements were presented. Then, teachers had to reflect upon communication level statements which map collaborative activities. Lastly, teachers reacted to statements, describing their institutional level. The last level refers to earlier studies which point out the important role of the school leadership in shaping the collaborative culture (Forte \& Flores, 2014) and the necessity of the resources (e.g. time and space) that are rooted in teachers' everyday routines (Vangrieken et al., 2015). During the individual interview, teachers contextualised and commented on the statements and their comments fed the discourse analysis. Each interview lasted one hour and was transcribed verbatim.

Critical discourse analysis was used as a method to analyse the material. Discourse is considered as a communication method in particular social, cultural, historical, and political situations (van Dijk, 2005).

The research highlights three main discourses. The collaborative discourse reveals the characteristics of the learning organisation. The competitive discourse: here the respondents do not accept all colleagues or leadership as partners, the satisfaction of the participants in the study is not as high as in collaborative discourse. The non-empowered teachers' discourse is characterised by non-messages. Here, teachers do not believe in collaboration, do not experience leadership support, and have no information or common understanding of the goals.

In the case of collaborative discourse the respondents speak with yesmessages, they use an active voice (I understand, we communicate), an indicative mood (they talk, they show), name the actors ( $I$, we, someone) and name themselves as active participants (I think, my opinion is), use verbs which represent collaborative actions (do, share, discuss). Collaboration means selfrealisation and meaningful work for respondents, learning and experimenting together, and development of the school. These teachers feel a responsibility towards school development. They feel autonomous because they are able to choose the development of activities. Referring to leadership, these teachers are involved in the decision-making processes, the choice of activities is put forward and their efforts recognised.

The discourse of competition is characterised by the fact that the teachers see themselves as resources and perceive (some) colleagues and/or leadership as obstacles. Some teachers describe witnessing partnership relations with colleagues and leadership at their schools. However they themselves keep passive due to lack of motivation, lack of time, interest and/or information. In comparison to the previous group, respondents use a passive voice (were put, was 
expected to do), and expressions that indicate compulsory collaboration (forced, must be done). Teachers indicate that they do not see themselves as creators of learning culture, nor do they see themselves as clearly accountable for it. They do not express interest in engagement. These teachers regard the school leadership as coercive and extortive.

The non-empowered teachers' discourse is perceived through no-messages (do not see, do not know, have not heard, did not do, do not know how, have not understood). Here, teachers report about lack of resources (time, etc.). These teachers do not believe in collaboration, they feel that they do not receive support from the leadership, do not have information or common understanding of the goals. They do not see their colleagues as resources, therefore, they point out activities that are foreseen by the leadership. These teachers use the noncollaborative linguistic expressions, such as are obliged to attend, was told to do so, the leadership is enforcing it on us and it must be done in collaboration. Teachers do not express autonomy in their activities; they do not see themselves influencing the learning culture at their schools. They do not formulate their own or school-related goals, nor perceive themselves as part of the school. They do not communicate with their colleagues, nor do they experience the options they are offered.

Based on the good practices outlined by the teachers in the study and which rely on the characteristics of the learning organisation, we suggest the ideas whereby school leadership can systematically support the collaborative culture at their schools. Namely, school leadership has a significant role in forming conditions for teachers' collaboration (Forte \& Flores, 2014; TALIS, 2008; Vangrieken et al., 2015).

1. Teachers are motivated by the possibilities to contribute to the school's development, having the opportunity to create collective vision; they are allowed to select roles, topics, workgroups, and practices. It is important to justify the need for collaboration, interpret the activities together, and take time for it.

2. Collegial learning and supporting each other through different collaborative networks creates a culture of everyday sharing and helps to avoid competition between teachers. The culture of lesson observation and feedback helps to create trust between teachers.

3. Systemic and consistent practices for sharing experiences and learning from each other in the physical environment that offers collaboration at a scheduled time (preferably in the middle of a working day), empowers teachers when adapting changes and implementing innovations. 
4. A common information field that takes into account teachers' needs, possibilities and habits (e-mails, message boards, verbal information and other information channels) fosters collaboration and inclusion.

5. Regular collaborative traditions jointly organised by teachers (sports, culture, community activities) significantly increase engagement and the sense of belonging.

6. Teachers' systematic empowerment raises self-efficacy in each teacher. An absence of fear of making mistakes increases the confidence and willingness of teachers to critically develop and test new methodologies and solutions.

7. Personal recognition of teachers, noticing their progress and effort and expressing it in different ways increases the work satisfaction.

Considering our numbers ( 15 general education schools and 45 respondents), we are able to draw conclusions about dominant discourses. However, it prevents us from evaluating the extent to which these discourse types would be populated within the overall Estonian school-landscape.

Keywords: collaborative learning culture, agency, teachers, critical discourse analysis 